\title{
DISTANCE-TRAINING FOR IMAGE-BASED 3D MODELLING OF ARCHEOLOGICAL SITES IN REMOTE REGIONS
}

\author{
V. Yordanov ${ }^{1,2}$, A. Mostafavi ${ }^{3}$, M. Scaioni ${ }^{4}$ \\ ${ }^{1}$ Vasil Levski National Military University, Veliko Tarnovo, Bulgaria \\ ${ }^{2}$ Dept. of Civil and Environmental Engineering (DICA) \\ Politecnico di Milano, Piazza Leonardo da Vinci 32, Milan, Italy - email: vasil.yordanov@polimi.it \\ ${ }^{3}$ Node-Office Tehran, Iran - email: armin.mstfv@gmail.com \\ ${ }^{4}$ Dept. of Architecture, Built environment and Construction engineering (DABC) \\ Politecnico di Milano, Via Ponzio 31, Milan, Italy - email: marco.scaioni@polimi.it
}

KEY WORDS: Archeology, Photogrammetry, Remote Areas, Structure-from-Motion, Training

\begin{abstract}
:
The impressive success of Structure-from-Motion Photogrammetry (SfM) has spread out the application of image-based 3D reconstruction to a larger community. In the field of Archeological Heritage documentation, this has opened the possibility of training local people to accomplish photogrammetric data acquisition in those remote regions where the organization of 3D surveying missions from outside may be difficult, costly or even impossible. On one side, SfM along with low-cost cameras makes this solution viable. On the other, the achievement of high-quality photogrammetric outputs requires a correct image acquisition stage, being this the only stage that necessarily has to be accomplished locally. This paper starts from the analysis of the well-know "3x3 Rules" proposed in 1994 when photogrammetry with amateur camera was the state-of-the art approach and revises those guidelines to adapt to SfM. Three aspects of data acquisition are considered: geometry (control information, photogrammetric network), imaging (camera/lens selection and setup, illumination), and organization. These guidelines are compared to a real case study focused on Ziggurat Chogha Zanbil (Iran), where four blocks from ground stations and drone were collected with the purpose of 3D modelling.
\end{abstract}

\section{INTRODUCTION}

The vaste Archeological Heritage on Earth may take great advantage from existing technology for 3D surveying and modelling, which play a paramount role in digital archiving, restoration, dissemination, and communication. In the past the photogrammetric surveying relied on the use of specific metric/semimetric cameras for data acquisition, and the use of complex analytical or digital procedure for extracting 2D and 3D information (such as plans, prospects, cross-sections, and orthophotos/rectified photos). On one side, the diffusion of digital non-metric cameras (see Waldhäusl and Ogleby, 1994) started to allow a dramatic cost reduction process in photogrammetric data acquisition. Thanks to rigorous but simple procedures, imaging sensors could be calibrated to obtain accurate metric outputs (Luhmann et al., 2016). On the other side, a progressive development of digital photogrammetry has undergone along with the impressive improvement of computing power of standard computers. But the most relevant step forward in image-based 3D modelling was the success of the so-called Structure-from-Motion Photogrammetry (in the sequel simply SfM). In a recent editorial, Granshaw (2018b) reviewed the origin of this technique that found its roots in both Photogrammetry (Luhmann et al., 2014) and Computer Vision (Hartley and Zisserman, 2006) domains. Originally, the term Structure-fromMotion only referred to the image orientation phase: at the very beginning considering the geometric model (Ullman, 1979), then including the automatic search for corresponding points using image matching (Snavely et al., 2006). In the last ten years, the popularity gained by this technique among nonspecialists, coupled with improvements in dense surface matching (Gruen, 2012), led to extend the term to cover both phases of image-based $3 \mathrm{D}$ reconstruction process.
By combining automatic image processing algorithms for image registration, which are robust against the use of convergent images and radiometric changes typical of close-range photogrammetric blocks, bundle adjustment (including selfcalibration) and dense surface matching techniques, SfM provides the users with an automatic pipeline to obtain efficient $3 \mathrm{D}$ reconstructions from images. This success is also motivated by the diffusion of powerful, easy-to-use and low-cost (or open source) software packages, which implement SfM in efficient way. After a few years when terrestrial laser scanning (TLS) sensors seemed to be the uncontrasted tools for 3D point cloud acquisition, SfM has granted again the photogrammetry as one of the leading techniques to this purpose. If compared to TLS, SfM has also the advantage of a much lower cost, in particular for purchasing the necessary hardware.

Today SfM is widely applied in many domains, including Cultural Heritage $(\mathrm{CH})$. Thanks to the economic sustainability and the apparent simplicity in its usage, SfM may be also operated by non-experts to survey archeological sites located in remote areas where specific surveying campaigns cannot be organized (see, e.g., Barazzetti et al., 2011). This includes the case of countries affected by war events or characterized by local unstable social/political condition, preventing experts to come from outside the region to carry out 3D surveying of the $\mathrm{CH}$. The use of amateur digital cameras, the availability of cheap small drones (see Granshaw, 2018a), and the chance of using low-cost photogrammetric packages, can be all together exploited by local people to do the 3D surveying operations.

On the other hand, while nowadays Photogrammetry has become a widely accessible and popular technique, the achievement of adequate results in the final products is not trivial. If the desired output is a good-looking 3D model for mere visualization purpose, also a low-quality point cloud can be textured to produce a model, whose geometric content is not 
sufficient for deeper analysis or to plan restoration actions. For such a reason, a set of guidelines may help non-expert users to improve their approach to SfM. On the other hand, to completely control the photogrammetric process a theoretical and practical background are both required, which should include several components: digital camera technology, network geometry, image processing, adjustment theory, elementary surveying, GNSS, photographic technique, photogrammetric and computer vision principles, and so on. But the knowledge of all these factors is still not enough in the case of poor experience. Training is then a pivotal task to achieve a qualified skill to accomplish SfM (Rutzinger et al., 2018). This is particularly important when dealing with $\mathrm{CH}$, which may require a level of accuracy and resolution of the final products that is bigger than the ones needed in other domains, such as in the Geosciences (Eltner et al., 2016).

In 1994, Waldhäusl and Ogleby published a paper reporting what it is well known as the " $3 \times 3$ Rules" for photogrammetry with non-metric cameras in the field of $\mathrm{CH}$ documentation. Such a set of guidelines were set up first to help students to carry out good photogrammetric projects. Then they have been extended and submitted to the CIPA-committee to become a standard. Following that concept, this paper would like to suggest an up-to-date version of the " $3 \times 3$ Rules" to be used within modern SfM for surveying projects in the field of $\mathrm{CH}$. In particular, the new proposed guidelines (Sect. 2) have been thought with the aim of supporting people to learn how to accomplish photogrammetric projects by themselves, without the help of experts. This capability could be useful to operate in those remote archeological areas that are difficult or even impossible to be reached by external experts, as discussed at the beginning of this section. Of course, as the authors of the " $3 \times 3$ Rules" in 1994 did make a proposal to be integrated and discussed in the scientific and practitioner community, the humble intention of this paper is again to make some suggestions only and to open a debate.

In order to better understand how the new guidelines for SfM may help in real applications, we aimed at the 3D reconstruction of Ziggurat Chogha Zanbil in Iran (Sect. 3). Though this can be accessed without any problem, the place has some characteristics that are typical of those remote archaeological areas where training local people would be a more viable way to collect 3D data. After the presentation of this example, some comparisons are proposed and discussed in Section 4. Eventually some conclusions are drawn in Section 5.

\section{GUIDELINES FOR SFM PHOTOGRAMMETRY}

\subsection{Review of the " $3 \times 3$ Rules"}

The " $3 \times 3$ Rules" were organized in three main sections, each of them consisting of three subsections. The first section deals with aspects related to the photogrammetric network geometry, such as the control information (scale bars, plumb-lines) and camera station geometry. It deserves to be observed that in the network two main functions are distinguished: the necessity of linking photos covering the whole object to survey and the presence of stereopairs for stereoplotting, that at the time was the approach used to derive $3 \mathrm{D}$ outputs. The same is recommended for the production of orthophotos and rectifications, which should be based on photos parallel to the main facades. The second section entails the photographic rules, including camera and lens selection, setup, and illumination. The third section lists some organization rules: the preparation of sketches, protocols and the final check.

Of course, some of these rules are now obsolete due to the transition from analogue to digital imaging technology. However, several practical rules are still valid, while others need to be updated to account for the acquisition methodology necessary when using SfM. In addition, the " $3 \times 3$ Rules" concern the data acquisition phase, which is only the first step of the photogrammetric process. Other rules may be added to guide the successive processing phase: camera calibration and image orientation, dense surface matching, point cloud processing, quality assessment, and production of final outputs. On the other hand, data acquisition is the crucial stage in order to set up a solid photogrammetric project, also because this task cannot be assisted as it happens in some popular photogrammetric software packages, where the user is guided along with the processing workflow. Furthermore, processing may be also done by expert people in a remote laboratory.

\subsection{Guidelines for data acquisition with SfM}

The conclusion of the analysis reported in the previous subsection is the relevance to have some guidelines to support data acquisition when using SfM in archeological applications. Following the scheme of the " $3 \times 3$ Rules", we discuss in the following geometric, imaging and organizational aspects. We consider in this section the planning of data acquisition from ground-based camera stations. Since drones (Granshaw, 2018a) are widely used in modern photogrammetric projects, when allowed by local regulations, the readers are suggested to refer to the specific literature (O'Connor et al., 2017; Pepe et al., 2018).

\subsection{Geometric aspects}

2.3.1 Control information. Very often, the precise georeferencing of a single project in a mapping reference system is not necessary or may be done using navigation-grade GNSS sensors, data from smartphones or using online geoportals. A local reference system is generally sufficient. Then the control information for the photogrammetric project only requires defining the scale of the $3 \mathrm{D}$ model and the local plumb-line direction. The following hints could be stated about this point:

- some known distances (e.g., scale bars) on the object may suffice to define the scale, provided that:

- distances are comparable to the object's size (do not use a one-metre bar to fix the distance for an object sizing 100 $\mathrm{m} !)$;

- distances are taken in different orthogonal directions, especially if the object has a complex shape;

- endpoints of each distance should be well defined; if possible, use targets to this purpose;

- define one or more plumb-lines to set up the vertical direction; and

- if the object has a complex shape or spans over a large area, split the survey into more photogrammetric projects, to be joined using some ground control points (GCP) measured using a theodolite. Some rules about the number of GCPs to be used may found in Scaioni et al. (2018). 
2.3.2 Network geometry. The geometry of the photogrammetric network is defined by the 3D position and attitude of each camera station. When using SfM, two different aspects should be balanced: (1) convergent photos and long baselines (i.e., the distances between camera stations) help the stability of the block geometry; (2) the presence of small (less than $10^{\circ}$ ) angles between adjacent photos makes easier the image matching at both orientation and dense matching stages (Barazzetti et al., 2009; 2011). Stereoplotting is generally not use any more for 3D modelling, which is based on extracting information from the point cloud obtained from dense matching. Considering these points, the following rules may be remembered:

- fix the average and the minimum value for the photo scale depending on the design resolution and precision. As a rule-of-thumb, consider the ground sampling distance (GSD), i.e., the average size ot the pixel footprint on the object as reference value. Remember that:

$$
\mathrm{GSD}=d(p z / c)
$$

While the pixel size $(p z)$ and the focal length $(c)$ both depend on the adopted sensor, the average distance camera-object $(d)$ can be selected, provided that geometric constraints in the nearby may limit the positioning of camera stations;

- the image acquisition should be based on sequences with $80 \%$ overlap and small relative rotation angles between consecutive images;

- sequences should be organized to follow the shape of the object along lines or rings;

- in the case of linear sequences, include some convergent photos ("arch bridge" rule), which play a twofold function of strengthening the network geometry (see Fraser, 1996) as well as to improve the visibility of those surfaces that are not parallel to the main sequence. An example of such a sequence in depicted in Figure 1;

- Add some $90^{\circ}$ rolled photos to improve camera calibration (roughly, one rolled photos every 10-15 photos may be enough);

- add sub-blocks to reconstruct details such as doors, decorations, bas-reliefs, regions with occlusions;

- capture images from half the object's height; if necessary, organize two overlapping sequences (keep at least 60\% sidelap between them);

- each item related to control information (plumb-lines, scale bars, targets) should be captured in at least three convergent images;

- check multiple coverage;

- add photos parallel to the object's facades to produce orthophotos or rectifications; and

- when using targets or scale bars/plumb-lines, take also photos from the same positions after removing them. While all photos will be processed together for image orientation, only the ones without targets (or scale bars/plumb-lines) will be exploited for surface reconstruction or texturing.

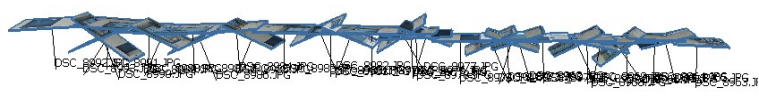

Figure 1. Example of acquisition of a linear sequence of images including alternate convergent photos ("arch bridge" rule).

\subsection{Imaging aspects}

2.4.1 Camera selection. Today the panorama of the available sensors for photogrammetric data acquisition is quite huge, including frame and panoramic cameras (Barazzetti et al., 2018). Cameras embedded in smartphones and action cameras have been proved to work well for SfM Photogrammetry as well. For other camera models or special lenses (e.g., fish-eyes) the reader is recommended to look the specialized literature. In the case of consolidated frame-camera technology, the following recommendations should be paid attention:

- try to avoid long focal lens (longer than $50 \mathrm{~mm}$ equivalent lens for $24 \times 36 \mathrm{~mm}$ full-format), except than in specific projects requiring acquisition from large distances;

- in general, large-format sensors may provide better image quality and less noisy images. Please note that here we refer to the physical sensor size, not to the number of pixels; and

- the use of more cameras is not suggested; if this option is needed, for example because of merging ground-based and drone-based photos, organize independent projects to be merged afterwards using GCPs, manually or automatically selected common points, or by merging point clouds (see Scaioni et al. 2018).

2.4.2 Camera setup. Some of the rules proposed in Waldhaeusl and Ogleby (1994) are still valid, to be integrated by additional requirements of digital imaging technology:

- do not change focal lens during your project:

turn off any autofocusing option;

- fix focal lens in the case of zoom-lens (use preferably the end position or fix the focal lens using a tape);

- turn off any function which may modify the original image geometry, such as spotting, automatic rotation of portrait photos, denoising filters;

- check out the correct recording of EXIF info in the image files;

- $\quad$ use the largest image size format available in the camera; and

- do not use small compression rates $(<95 \%$ in the case of JPG).

2.4.3 Scene illumination. In digital imaging the problem of poor lighting cannot be overcome by rising the sensibility (higher ISO values), which result in more noise in the image content. Some recommendations should be remembered:

- select the best time of day, to guarantee a sharp lighting and mitigate the effect of shadows;

- do not operate in windy conditions, that also change shadows quickly;

- use tripod or other stabilizing tools; and

- shot photos using timer function in the case of hand-held acquisition.

\subsection{Organizational aspects}

Under this aspect, the content of the " $3 \times 3$ Rules" is still valid and should be carefully considered. For this reason, we do not revise this topic here. 


\section{APPLICATION}

\subsection{The Ziggurat Chogha Zanbil}

The southwest of Iran - an area not far from the domains of the Zagros Mountains, between two large rivers named Karoon and Dez - is the birthplace of the great kingdom of Elam in ca. 4000 B.C. (Potts, 1999). As can be seen in Figure 2, this region is located $90 \mathrm{~km}$ north of the city of Ahvaz and $35 \mathrm{~km}$ south of the ancient city of Susa (Emami, 2012).

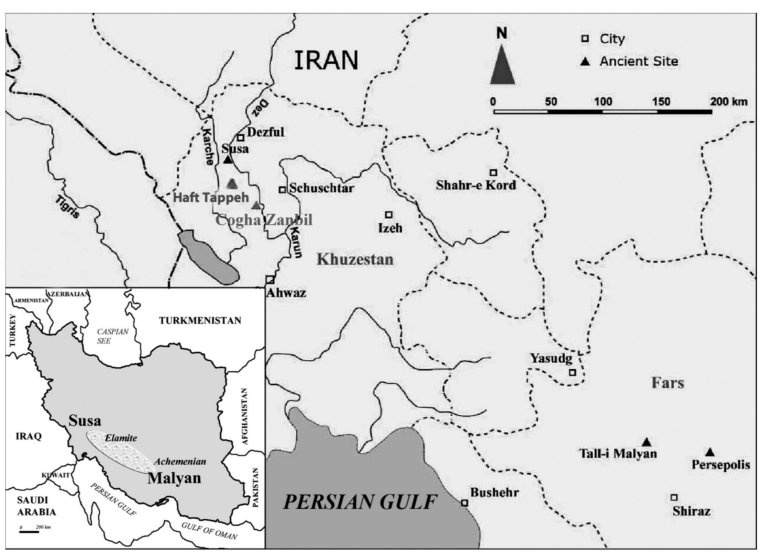

Figure 2. Geographic location of the Ziggurat Chogha Zanbil (Iran).

Ziggurat Chogha Zanbil (Carter, 1996) is located in a settlement founded by the Elamite king Untaš Napiriša (The Elamite name of this structure is Ziggurat Dūr Untash), see Figure 3. The outer enclosure wall is about $1,300 \mathrm{~m} \times 1,000 \mathrm{~m}$ while the second and third inner enclosures size $400 \mathrm{~m} \times 400 \mathrm{~m}$ and 200 m x 180 m, respectively (see a map in Fig. 4). The remains of the Ziggurat stand up to a height of more than $25 \mathrm{~m}$, structured on three levels above the surrounding pavement (see Figs. 3 and 4). Originally, it consisted of five levels rising up to $53 \mathrm{~m}$. The material used for construction is mud-bricks for the core, which are covered of baked bricks layer $2 \mathrm{~m}$ thick.

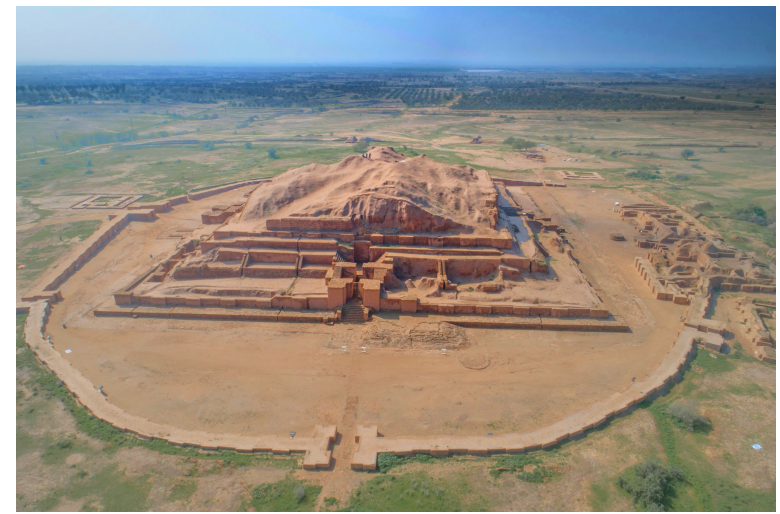

Figure 3. Aerial view of the Ziggurat Chogha Zanbil.

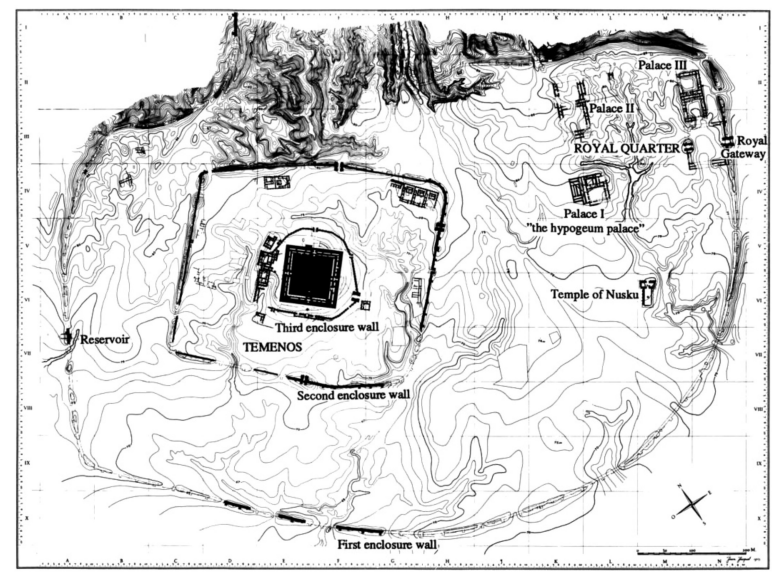

Figure 4. Topographic map of Ziggurat Chogha Zanbil (from Ghirshman, 1966)

\subsection{Photogrammetric data sets}

The surveyed area of the Ziggurat Chogha Zanbil was inside the $3^{\text {rd }}$ enclosure wall, chiefly consisting of the Ziggurat building (approx. 20,000 $\mathrm{m}^{2}$ ). Because of the construction's complexity, four photogrammetric data sets were collected:

1. Ground-based (GB) photos;

2. Low-angle oblique UAV photos (LAOUAV);

3. High-angle oblique UAV photos (HAOUAV); and

4. Nadir UAV photos (NUAV).

Figure 5 reports some typical camera standpoints for different blocks, which are described in the following paragraphs.

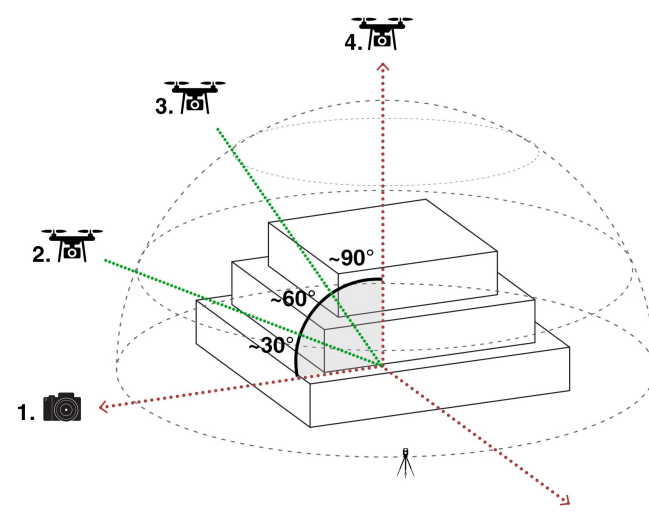

Figure 5. Typical camera standpoints for the photogrammetric data sets.

In addition, seven GCPs were measured. These were positioned either in the surrounding area of the Ziggurat and on the Ziggurat itself. The CGP positions are shown in Figure 6. Some GCPs were located off-ground in order not let them all lie on a plane. Indeed, GCP A6 is located on the first level of the Ziggurat and GCP A7 is on the top of the upper inner part. The 
GCP coordinates were measured using a multi-frequency GNSS sensor (SOUTH - Galaxy G1 Plus).

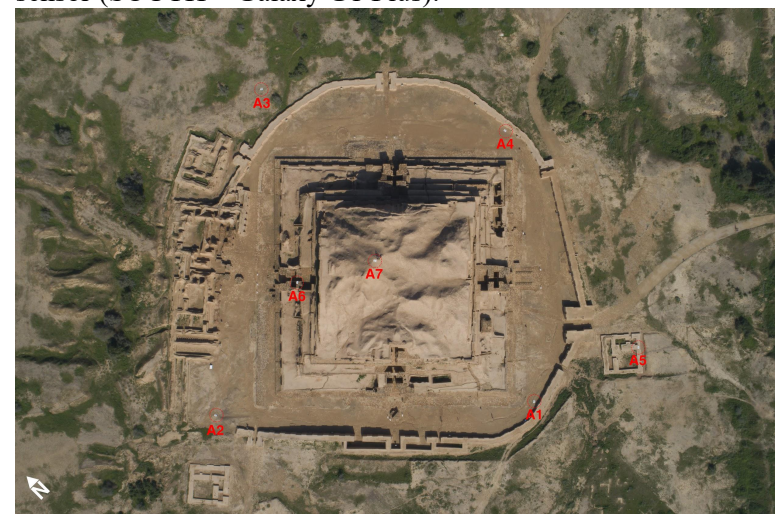

Figure 6. - Planimetric positions of GNSS GCPs.

3.2.1 Ground-based block (GB). The GB Data Set (Fig. 7) was planned to cover the vertical facades of the Ziggurat from camera stations located at approximately $1.7 \mathrm{~m}$ from ground. A Sony alpha 7RII SLR (single-lens reflex) camera equipped with $16 \mathrm{~mm}$ lens was used (see Table 1). It consisted of four linear sequences including some convergent photos, as suggested in paragraph 2.3.2. It was ensured that terrestrial photos were taken at a sufficient distance $(\sim 15-20 \mathrm{~m})$ with $80 \%$ overlap to guarantee a GSD between $2-3 \mathrm{~cm}$. Some convergent photos around corners were collected to connect linear sequences. Obviously, this data set is not able to capture the upper part of the Ziggurat.

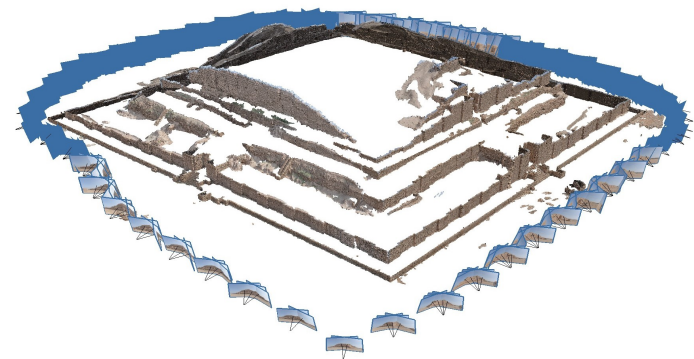

Figure 7. Camera poses of GB Data Set.

\begin{tabular}{|l|l|l|l|}
\hline $\begin{array}{l}\text { Instrumen } \\
\mathrm{t}\end{array}$ & Name & Specification \\
\hline $\begin{array}{l}\text { Terrestrial } \\
\text { Camera }\end{array}$ & Sony alpha 7RII & $\begin{array}{l}\text { lens } 16- \\
50 \mathrm{~mm} \text { Sony } \mathrm{f} / 3.5-5.6 \\
\text { OSS }\end{array}$ & Layer 01 has 212 photos \\
\hline $\begin{array}{l}\text { Aerial } \\
\text { Camera }\end{array}$ & $\begin{array}{l}\text { DJI Phantom 4 Pro } \\
\text { Plus }\end{array}$ & $\begin{array}{l}\text { Lens : FOV } 84^{\circ} 8.8 \\
\mathrm{~mm} / 24 \mathrm{~mm}(35 \mathrm{~mm} \\
\text { format equivalent) } \mathrm{f} / 2.8- \\
\mathrm{f} / 11\end{array}$ & $\begin{array}{l}\text { Layer } 02 \text { has } 75 \text { photos } \\
\text { Layer } 03 \text { has } 107 \text { photos } \\
\text { Layer 04 has } 160 \text { photos }\end{array}$ \\
\hline
\end{tabular}

Table 1. Main properties of sensors adopted to collect photogrammetric data sets.

3.2.2 Oblique UAV blocks (LAOUAV/HAOUAV). A couple of UAV data sets using oblique setup were thought as a tradeoff to cover both vertical walls and the upper part of the site. For this reason, two different inclination angles have been tried $\left(30^{\circ}-60^{\circ}\right)$, each of them consisting on a circular sequence around the Ziggurat. Dense image matching of oblique images permits to include the façade description and the building footprints in the models. All UAV missions were operated using a DJI Phantom 4 Pro Plus carrying an $8.8 \mathrm{~mm}$ lens camera (see Table 1).

In the case of low-angle oblique UAV block (LAOUAV), one full circular (average diameter $\mathrm{d}=140 \mathrm{~m}$ ) image sequence was captured at approximately $20 \mathrm{~m}$ relative height from ground and orientation about $30^{\circ}$ from the local horizontal plane. This block resulted in 10-12 images per facade.

In the case of high-angle oblique UAV block (HAOUAV), to avoid blurry images caused by wind exist on surveying site, two full circulars (average diameter $\mathrm{d}_{1}=210 \mathrm{~m}$ and $\mathrm{d}_{1}=270 \mathrm{~m}$ ) sequences at approximately $45 \mathrm{~m}$ and $50 \mathrm{~m}$ relative height from ground with orientation about $60^{\circ}$, while the onboard camera was roughly $45^{\circ}$ oriented toward the Ziggurat (see Fig. 8). The number of images for each facade (15-17) was higher than in the case of LAOUAV Data set.

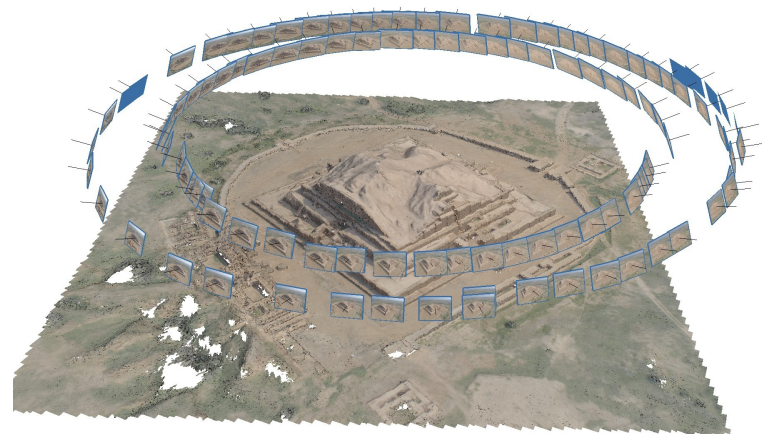

Figure 8. Camera poses of HAOUAV Data Set, which consists of two circular sequences around the Ziggurat.

3.2.3 Nadir UAV blocks (NUAV). The UAV block based on nadir photos (see Fig. 9) is suitable for collecting the ground surface and the upper part of the construction but cannot properly cover vertical surfaces. UAV surveys are usually nadir, which means that the images are shot with the camera axis along the vertical direction; they provide both a forward overlap between shots and a side one between strips, allowing the reconstruction of the surveyed t object in 3D (Vacca et al., 2017). In our case study, an approximate $50 \mathrm{~m}$ relative height from ground on a linear grid pattern was selected. A total number of 160 images were taken in order to cover all $3^{\text {rd }}$ enclosure wall area (approx. 4,000 $\left.\mathrm{m}^{2}\right)$.

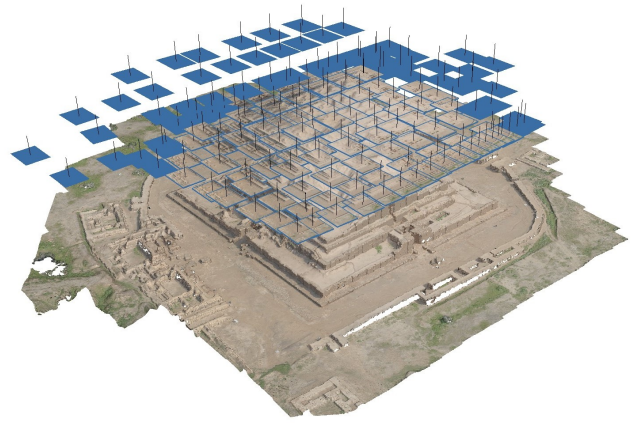

Figure 9. Camera poses of NUAV Data Set. 


\subsection{Data processing}

3.3.1 Pre-processing. After the acquisition stage one should manually verify the quality of the obtained images. Where photos with shifted focus location or totally out of focus should be removed, the latter is also valid for images blurred during the capture process (e.g., tremble during hand-held acquisition in low-light conditions - see recommendations at par. 2.4.3). This check-out is suggested to be done on-site, so that some photos may be recaptured, if necessary. In general, the acquisition of a good data set will ensure the quality of next modelling stages, as well it will save time and financial costs, especially in areas not easy to access.

In some cases, it is hard for one to choose the best illumination conditions. Therefore, some processing of the images could be applied, just for the purpose of extracting useful information from them (e.g., in case of large shadows). Where most of the suggested actions are related to colour balancing, exposure equalization and denoising may be applied (Ballabeni et al., 2015). While some photometric manipulations do not affect the following reconstruction, other manipulations such as cropping, resizing or rotating the images are not suggested. During the pre-processing actions, it is important that the EXIF information is not lost, since its valuable information of the sensor size and focal length parameters is crucial for the camera calibration. It is worth noting, that all pre-processing manipulations should be applied to the whole dataset.

3.3.2 Structure-from-Motion Photogrammetry. Nowadays, there is a great variety of photogrammetric software solutions implementing the SfM processing pipeline. Here we adopted Agisoft Metashape ${ }^{\circledR}$ (AMs) ver. 1.5.0, which is a popular SW package adopted in several domains. The same processing pipeline was adopted for different blocks, which were processed independently.

The image orientation ("alignment" in the AMs jargon) was operated by using images at original full resolution (while AMs also allows to work with subsampled images in the case of very large projects or when a lower resolution of the outputs is enough). The camera parameters' estimation was performed during the bundle adjustment applied to compute camera orientation and 3D coordinates of automatically extracted tie points (Barazzetti et al., 2011), which define the so-called "sparse point cloud." Camera calibration and orientation were computed per each data set of photos.

After "alignment", the dense matching function was applied to densify the "sparse point clouds" and obtain "dense point clouds." Further edit of the point cloud is suggested, where all of points created outside the area of interest should be removed.

After obtaining dense point clouds (see, e.g., Figs. 10 and 11) from different data sets, one can combine them in one single block, which will improve the overall quality and increase the details in parts where single blocks could not provide a complete point cloud. For example, from NUAV Data Set we obtained a point cloud which did not contain detailed information of facades. On the contrary, GB Data Set resulted in opposite performances. A combination between point clouds achieved from different blocks may performed better (see an example in Fig. 12). The merge of multiple point clouds can be done using common GCPs. When this solution cannot be pursued (e.g., GB Data Set does not contain GCPs shared with
UAV blocks), a manual measurement of corresponding features is suggested to merged point clouds.

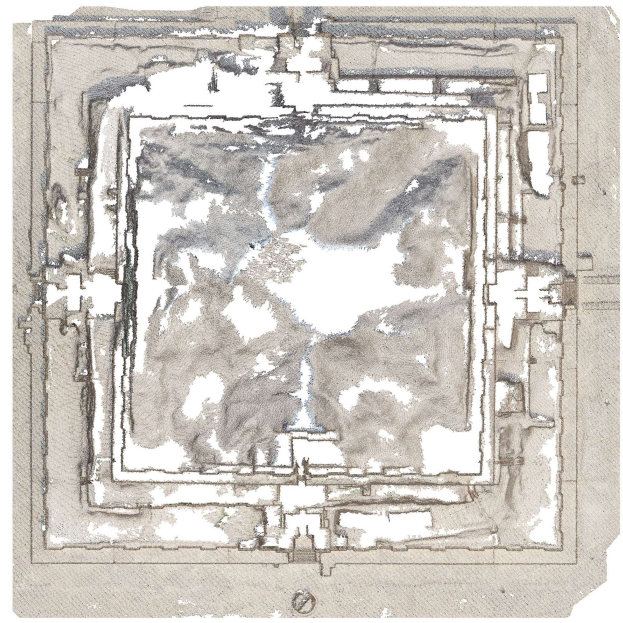

Figure 10. Top view of the LAOUAV dense point cloud.

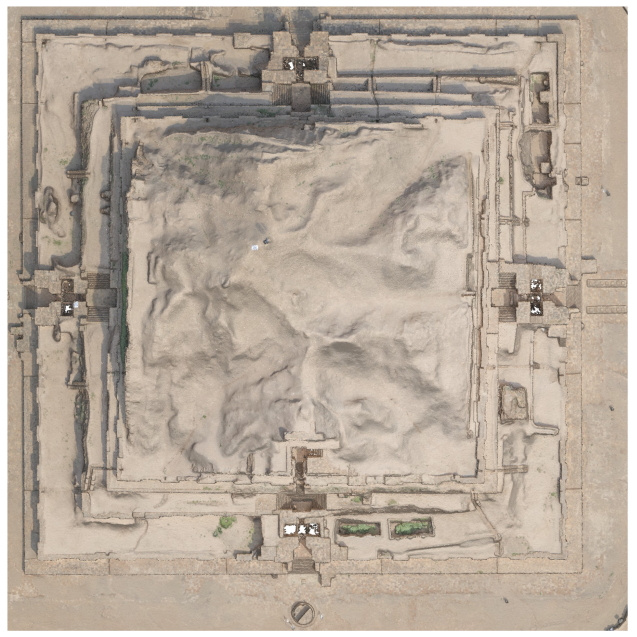

Figure 11. Top view of the NUAV dense point cloud.

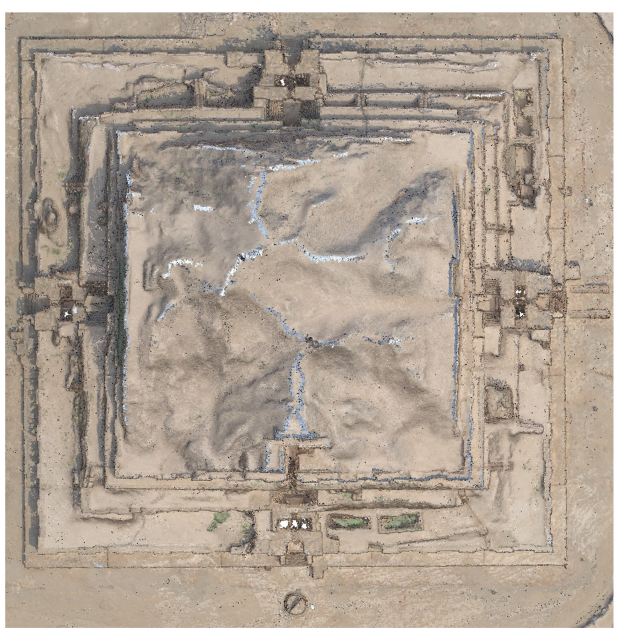

Figure 12. Top view of the merged point cloud. 


\section{DISCUSSION}

The data processing pipeline described in Subsection 3.3 was independently applied to all data sets captured on the Ziggurat (see Subsect. 2.3). In Table 2 some details about obtained point clouds and their accuracy can be found. It can be noted that the highest accuracy was achieved from NUAV Data Set. On the contrary, there is no information about the accuracy of GB Data Set since no GCPs were present. On the other hand, each point cloud contributed to a merged point cloud with a global accuracy of approximately $8 \mathrm{~cm}$ in term of RMSE (Root Mean Square Error) on GCP residuals. In the meantime, the latter effect is clear visible on the facades of the temple, where the merged clouds yield higher level of details and lack of holes with missing information. Nevertheless, a more thorough comparison between the clouds is needed to determine the coregistration accuracy between the individual blocks. For that purpose, the tool Cloud-2-Cloud (C2C) distance in the opensource software package CloudCompare ${ }^{\circledR}$ (www. cloudcompare.org) is suggested. In the comparison phase it is preferred to use the cloud that is the most accurately georeferenced as reference and compare others to that. In our case, NUAV point cloud was selected to this purpose. It should be noted, that point clouds were subsampled at $10 \mathrm{~cm}$ minimum distance between points in order to save memory and computational time.

\begin{tabular}{|c|c|c|}
\hline Point cloud Data Set & $\begin{array}{c}\text { \# points } \\
{[\mathbf{M}]}\end{array}$ & $\begin{array}{c}\text { RMSE of GCP } \\
\text { residuals }[\mathbf{c m}]\end{array}$ \\
\hline GB & 75.0 & Not available \\
\hline LAOUAV & 141.6 & 19.8 \\
\hline HAOUAV & 67.4 & 9.6 \\
\hline NUAV & 80.2 & 3.4 \\
\hline Merged & 364.2 & 8.1 \\
\hline
\end{tabular}

Table 2. Point clouds' information.

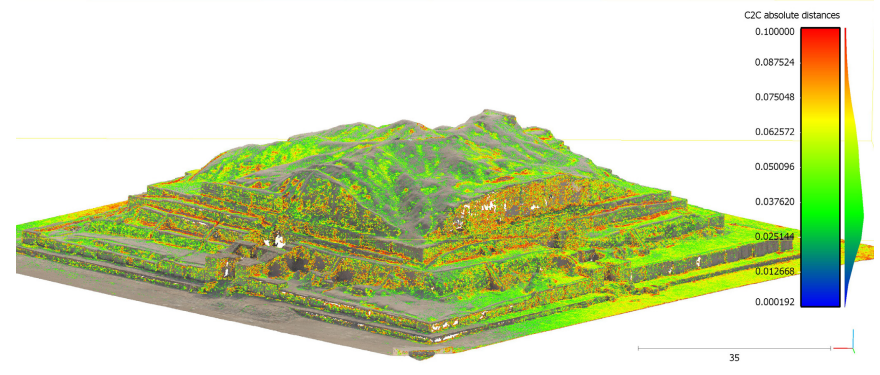

Figure 13. C2C distance comparison between NUAV and HAOUAV clouds.

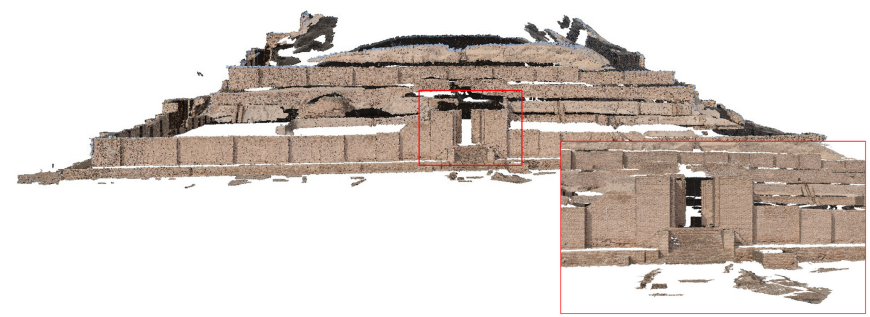

Figure 14. Facade view of the GB cloud with an aspect to the details of the cloud.

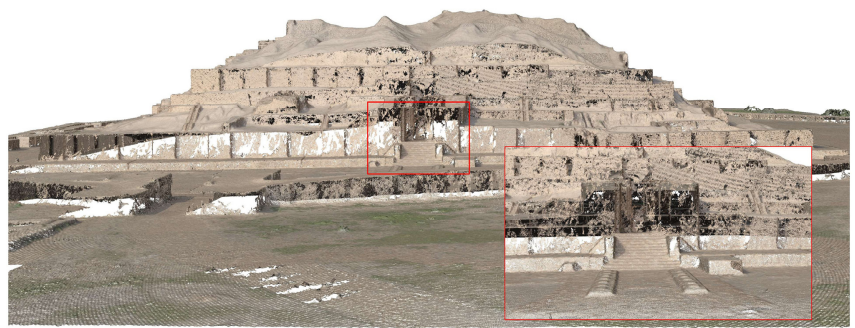

Figure 15. Facade view of the NUAV cloud representing different level of details.

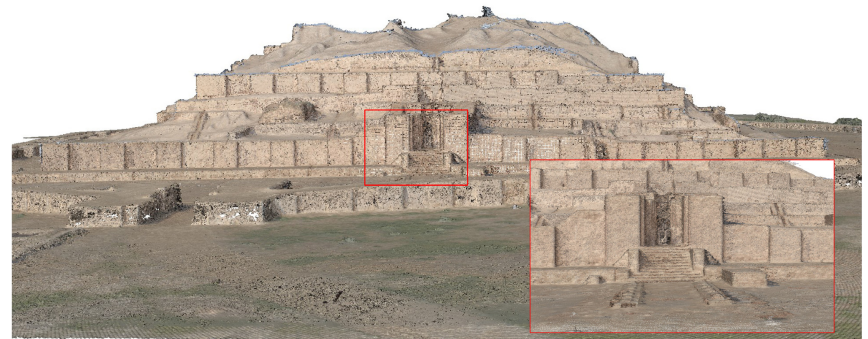

Figure 16. Facade view of the merged point cloud. 
In Figure 13 an example of comparison (NUAV and HAOUAV point clouds) is shown. One can note that the actual differences between both clouds are quite small $(<10 \mathrm{~cm}$ in absolute value), and comparable with the final point cloud resolution. The largest dissimilarities are in areas affected by strong shadows, or in where less GCPs were available for the merging point clouds. In addition, it is apparent the effect on the oblique clouds and their contribution to the details of the facades. Of course, the integration of point clouds from GB and NUAV Data Sets represents the trade-off between those two acquisition modes (Figs. 14 and 15), but the overall contribution of all Data Sets to the final cloud is clear in Figure 16.

\section{CONCLUSIONS}

In this paper some guidelines to accomplish photogrammetric data acquisition of an archeological site have been presented. The suggested methodology has been drawn in view of the application of Structure-from-Motion Photogrammetry (SfM). In particular, these guidelines have been defined to allow nonexpert people to operate in remote areas where archeological sites may be located.

The presentation of a case study related to the Ziggurat Chogha Zanbil (Iran) has demonstrated that the proposed guidelines are useful to drive people who have to plan and operate photogrammetric data acquisition in a typical remote archeological area.

Those guidelines do not have a definitory character, but they would call for the attention of the scientific community towards the necessity to develop and share best practices and standards. Here we have limited the attention to the data acquisition stage, that necessarily has to be done on site. For this reason, training of local people is a fundamental task. On the other hand, also the successive steps of the SfM pipeline, such as the point cloud generation, modelling and the extraction of final outputs, need to be paid attention and to be focused in future papers.

\section{Acknowledgements}

The authors would like to thank Agisoft company (St. Petersburg, Russia) for the availability of trial licenses of Agisoft Metashape $^{\circledR}$.

\section{REFERENCES}

\section{References from books}

Carter, E., 1996. $\check{C} O \bar{G} \bar{A} Z A N B \bar{I} L$. Encyclopædia Iranica, Vol. VI, Part 1 , pp. 9-13, available online at http://www. iranicaonline.org/articles/coga-zanbil (last accessed on 21st March 2019).

Fraser, C.S., 1996. Network design. Close Range Photogrammetry and Machine Vision. (Ed. K.B. Atkinson). Whittles Publishing, Caithness, Scotland. 371 pages: 256-281.

Ghirshman,R., 1966. Tchoga Zanbil(Dur-Untash) I. La ziggurat. MDAFI 39, Paris, 1966.

Hartley, R., Zisserman, A., 2006. Multiple View Geometry in computer vision. Cambridge University Press, UK.

Luhmann, T., Robson, S., Kyle, S., Boehm, J., 2014. Close Range Photogrammetry: 3D Imaging Techniques - 2nd Edition. Walter De Gruyter Inc., Germany, 684 pages.

Potts, D.T., 1999. The Archaeology of Elam Formation and Transformation of an Ancient Iranian State From. Cambridge World Archaeology.

\section{References from journals}

Barazzetti, L., Binda, M.L., Scaioni, M., Taranto, P., 2011. Photogrammetric survey of complex geometries with low-cost software: application to the 'G1' Temple in Myson, Vietnam. J.Cult. Heritage, 12(2011): 253-262.

Eltner, A., Kaiser, A., Castillo, C., Rock, G., Neugirg, F., Abellán, A., 2016. Image-based surface reconstruction in geomorphometry-merits, limits and developments. Earth Surf Dyn, Vol. 4:359-389.

Emami, M., Trettin, R., 2012. Mineralogical and chemical investigations on the ceramic technology in Čogā Zanbil, (Iran, 1250 B.C.). Period Mineral., vol. 81(3):359-377

Ghirshman, R., 1960. The Ziggurat of Tchoga-Zanbil. Sci. Am., Vol. 204(1): 68-76

Granshaw, S.I., 2018a. RPV, UAV, UAS, RPAS ... or just drone? Photogramm. Rec., 32(162): 160-170.

Granshaw, S.I., 2018b. Structure from Motion: Origins and Originality. Photogramm. Rec., 33(161): 6-10.

Luhmann, T., Fraser, C.S., Maas, H.-G., 2016. Sensor Modelling and Camera Calibration for Close Range Photogrammetry. ISPRS J. Photogramm. Remote Sens., Vol. 115: 37-46.

O’Connor, J., Smith, M.J., James, M.R., 2017. Cameras and settings for aerial surveys in the geosciences: Optimising image data. Prog Phys Geog, Vol. 41:325-344.

Pepe, M., Fregonese, L., Scaioni, M., 2018. Planning Airborne Photogrammetry and Remote-Sensing Missions with Modern Platforms and Sensors. Eur. J. Remote Sens., Vol. 51(1): 412-435, DOI: 10.1080/22797254.2018.1444945.

Snavely, N., Seitz, S.M., Szeliski, R., 2006. Photo tourism: Exploring photo collections in 3D. ACM Trans. Graphics, Vol. 25(3): 835-846.

Ullman, S., 1979. The interpretation of structure from motion. Proc. Royal Soc. London, Series B, Biolog. Sci., Vol. 203:405-426.

Vacca, G., Dessì, A., Sacco, A., 2017. The Use of Nadir and Oblique UAV Images for Building Knowledge. ISPRS Int. J. Geo-Inf., Vol. 6(12), paper no. 393.

\section{References from proceedings}

Ballabeni, A., Apollonio, F. I., Gaiani, M., Remondino, F., 2015. Advances in image pre-processing to improve automated 3D reconstruction. Int. Arch. Photogramm. Remote Sens. Spatial Inf. Sci., Vol. XL-5/W4, pp. 315-323.

Barazzetti, L., Remondino, F., Scaioni, M., 2009. Combined use of photogrammetric and computer vision techniques for fully automated and accurate 3D modeling of terrestrial objects. In: Videometrics, Range Imaging, and Applications X, Proc. of SPIE, paper no. 74470M.

Barazzetti, L., Forlani, G., Remondino, F., Roncella, R., Scaioni, M., 2011. Experiences and achievements in automated image sequence orientation for close-range photogrammetric projects. In: Videometrics, Range Imaging, and Applications XI, Proc. of SPIE, paper no. 80850F.

Barazzetti, L., Previtali, M., and Roncoroni, F., 2018. Can we use lowcost 360 degree cameras to create accurate 3D models? Int. Arch. Photogramm. Remote Sens. Spatial Inf. Sci., Vol. XLII, Part 2:69-75.

Rutzinger, M., Bremer, M., Höfle , B., Hämmerle, M., Lindenbergh, R., Oude Elberink, S., Pirotti, F., Scaioni, M., Wujanz, D., Zieher, T., 2018. Training in Innovative Technologies for Close-Range Sensing in Alpine Terrain.ISPRS Ann. Photogramm. Remote Sens. Spatial Inf. Sci., Vol. IV, Part 2, pp. 239-246, DOI: 10.5194/isprs-annals-IV-2-2392018.

Scaioni, M., Crippa, J., Corti, M., Barazzetti, L., Fugazza, D., Azzoni, R., Cernuschi, M., Diolaiuti, G.A., 2018. Technical Aspects Related to the Application of SfM Photogrammetry in High Mountain. Int. Arch. Photogramm. Remote Sens. Spatial Inf. Sci., Vol. XLII, Part 2: 10291036.

Waldhaeusl, P., Ogleby, C., 1994. 3 x 3 rule for simple photogrammetric documentation of architecture. Int. Arch Photogramm. Remote Sens. Spat. Inf. Sci., Vol. XXX, Part 5: 426-429. 